quả càng tốt . Kết quả: Thời gian nằm viện trung bình là $10 \pm 4.6$ ngày. Thời gian nằm viện ngắn nhất là 5 ngày, dài nhất là 26 ngày. Kết quả chung tốt chiếm $70.6 \%$, có 4 bệnh nhân chiếm $11.8 \%$ có biến chứng máu đông màng phổi phải mổ nội soi xử lý ổ cặn. Theo kết quả của Nguyễn Hữu Ước ${ }^{1}$ và cộng sự thì thời gian nằm viện trung bình với nhóm bệnh nhân chấn thương ngực đơn thuần là $5,3 \pm 4,9$ ngày, tỷ lệ tốt là $89.9 \%$, không tốt là $5.7 \%$, còn theo Chrysou Konstantina ${ }^{6}$ và cộng sự với nhóm chấn thương ngực trên các bệnh nhân đa chấn thương thời gian nằm viện trung bình là 11 ngày, tương đương với kết quả nghiên cứu của chúng tôi.

\section{KẾT LUÂ̂N}

Chấn thương ngực kèm theo chấn thương so não có dẫn lưu màng phổi đơn thuần là một trong những là một bệnh cảnh lâm sàng nặng, chăm sóc và điều trị đòi hỏi tính chuyên khoa. Kết quả chăm sóc và điều trị nhóm bệnh nhân nghiên cứu phản ánh thực trạng loại hình thương tổn phối hợp này và cho kết quả khả quan.

\section{TÀl LIÊU THAM KHẢO}

1. Nguyễn Hữu Ước và công sự. Đánh giá tình hinh cấp cứu chấn thương lî̀ng ngực tại bệnh viện Việt Đức từ 2004 - 2006. Tạp chí Ý học Việt Nam. 2007;328:402-413.
2. Huang F-D, Yeh W-B, Chen S-S, et al. Early Management of Retained Hemothorax in Blunt Head and Chest Trauma. World J Surg. 2018;42(7):2061-2066.

3. Nguyễn Thế Hiệp, Lê Nữ Hòa Hiêp, Nguyễn Hoài Nam và cộng sự. Kết quả điểu trị chấn thương và vết thương ngực tại bệnh viện nhân dân Gia Định - TP.HCM. Tạp chí y học Việt Nam. 2008;352:483-490.

4. Zargar M, Khaji A, Karbakhsh Davari M Thoracic injury: a review of 276 cases. Chin J Traumatol. 2007;10(5):259-262.

5. Nguyê̂̉n Trường Giang, Nghiêm Đình Phấn, Nguyển Văn Sơn, Đăng Ngoc Hùng. Đăc điểm tôn thương và chiến thuật xự trí chấn thương ngực trong đa chấn thương. Tổng hội $Y$ Dược học. 2006; Ngoai khoa(6):12-17.

6. Chrysou K, Halat G, Hoksch B, Schmid RA, Kocher GJ. Lessons from a large trauma center: impact of blunt chest trauma in polytrauma patients-still a relevant problem? Scand J Trauma Resusc Emerg Med. 2017;25(1):42.

7. Hildebrand F, Giannoudis PV, Griensven M van, et al. Management of polytraumatized patients with associated blunt chest trauma: a comparison of two European countries. Injury. 2005;36(2):293-302.

8. Đặng Ngọc Hùng và cộng sự. Một số nhận xét về đắc điểm triêuu chứng, sơ cứu và cấp cứu chấn thương ngực kín qua 139 trường hợp tại bệnh viện 103. Tap chí ngoại khoa. 2006;56(6):2-11.

9. J. Hugh Devitt. Blunt Chest Trauma: Anaesthesia, assessment and management. In: Can J Anaesth. 40th ed.; 1993:29-39.

\title{
VAI TRÒ CỦA CEA TRONG ĐÁNH GIÁ ĐÁP ỨNG HÓA TRI UNG THƯ ĐẠI TRỰC TRÀNG GIAI ĐOẠN TÁI PHÁT, DI CĂN
}

\section{TÓM TẮT}

Mục tiêu nghiên cứu: Đánh giá vai trò của carcinoembryonic antigen (CEA) trong việc theo dõi đáp ứng khối u với hóa trị trong điêu trị ung thư đại trực tràng (UTĐTT) giai đoạn tái phát, di cắn không mổ được tại khoa Nội 4 Bệnh viện $K$ từ tháng 7/2017đến tháng 7/2021. Đối tượng và phương pháp nghiên cứu: Nghiên cứu mô tả hồi cứukết hợp với tiến cứu trên 81 bênh nhân UTĐTT giai đoạn tái phát, di căn không mổ được có tăng CEA >5ng/ml trước điều trị, sử dụng hóa chất phác đồ có Oxaliplatin hoặc Irinotecan làm nền, 6 chu kì hóa trị. Nông độ

${ }^{1}$ Trương Đại học Y Hà Nội

²Bênh viện $K$ Tân Triều, thành phố Hà Nội.

${ }^{3}$ Bệnh viện Ung Bướu Hà Nội, thành phố Hà Nội.

Chịu trách nhiệm chính: Phan Văn Quân

Email: Phanquanhmu@gmail.com

Ngày nhận bài: 9.7.2021

Ngày phản biên khoa họ: 3.9.2021

Ngày duyệt bài: 10.9.2021
Phan Văn Quân ${ }^{1}$, Trần Thắng², Bùi Vinh Quang ${ }^{3}$

CEA huyết tương và chụp cắt lớp vi tính (CLVT) được thực hiện trước điều trị và sau mỗi 03 chu kì hóa trị. Kết quả: Độ nhạy, độ đặc hiệu, giá trị dự đoán dương tính, âm tính, độ chính xác chẩn đoán của việc đánh giá đánh ứng bằng CEA đối với bênh đáp ứng hoàn toàn và một phân lần lượt là $82,0 \%, 63,1 \%$, $63,1 \%, 82,0 \%, 71,3 \%$, đối với bểnh tiến triên lần lướt là $61,1 \%, 80,4 \%, 36,7 \%, 91,8 \%$. Kết luận: Nồng độ CEA huyết thanh có thể cung cấp thông tin hữu ích trong đáp giá bệnh đáp ứng và tiến triển ở bệnh nhân UTĐTT giai đoạn tái phát, di căn không mổ được có tăng CEA trước điều trị.

Tư khóa: ung thư đại tràng, trực tràng, giai đoạn tái phát, di căn, CEA.

\section{SUMMARY \\ THE ROLE OF CARCINOEMBRYONIC ANTIGEN FOR MONITORING TUMOUR RESPONSE DURING CHEMOTHERAPY IN RECURRENT, METASTATIC COLORECTAL CANCER \\ Aims: To evaluate the efficacy of carcinoembryonic antigen (CEA) for monitoring tumour}


response during chemotherapy in recurrent, metastatic colorectal cancer (CRC). Patients and method: Retrospective description study of 81 recurrent, metastatic colorectal cancer patients that had initial CEA level more than $5 \mathrm{ng} / \mathrm{ml}$ and treated with Oxaliplatinbased or Irinotecan-based chemotherapy. Serum CEA levels were measured and computed tomography (CT) workups were performed before chemotherapy treatments and after every 3 cycles of chemotherapy. Results: The sensitivity, specificity, positive predictive value, negative predictive value, and diagnostic accuracy of CEA assessment for prediction of disease response (complete or partial) and progression were $82,0 \%, 63,1 \%, 63,1 \%, 82,0 \%, 71,3 \%$ and $61,1 \%$, $80,4 \%, 36,7 \%, 91,8 \%$ respectively. Conclusions: SerumCEA levels could be useful for monitoring tumour response and progression during chemotherapy in recurrent, metastatic colorectal cancer in patients with initially elevated CEA level.

Key words: Colorectal cancer, recurrent, metastatic stages, CEA.

\section{I. ĐẶT VẤN ĐỀ}

Tiên lượng của UTĐTT giai đoạn tái phát di căn đã dần được cải thiện trong hởn 10 năm trở lại đây nhờ các tiến bộ trong điều trị toàn thân. Trước đây, với phác đồ chứa fluropyrimidine đơn thuần, thời gian sống thêm của người bệnh chỉ đạt dưới 1 năm, nhưng gần đây, với sự phát triển của các thuốc mới như thuốc điều trị đích và miễn dịch cùng với chiến lược điêuu trị hợp lý đã giúp kéo dài thời gian sống thêm của các bệnh nhân ở giai đoạn này đến hơn 30 tháng[1]. Để đạt được kết quả như vậy các nhà lâm sàng cần có một kế hoạch điều trị cụ thể ngay từ đầu đồng thời phải theo dõi đáp ứng điều trị. Trên thực tế, mục đích của việc theo dõi sát kết quả điều trị nhằm phát hiện các trường hợp bệnh tiến triển để thay đổi phác đồ điều trị kịp thời giúp cho bệnh nhân có cơ hội được tối ưu hóa kết quả điều trị.

Trong thực hành lâm sàng, việc đánh giá đáp ứng của các khối u đặc nói chung và UTĐTT nói riêng chủ yếu dựa vào các thăm khám lâm sàng và các thay đổi trên chẩn đoán hình ảnh theo tiêu chuẩn về đáp ứng của khối u RECIST. Bên cạnh các phương pháp đánh giá kết quả bằng lâm sàng và hình ảnh, một số tác giả đã đề xuất đưa CEA (carcinoembryonic antigen) như một yếu tố đánh giá và theo dõi điều trị UTĐTT, tuy nhiên vấn đề này còn gặp nhiều tranh luận.

Chính vì vậy chúng tôi tiến hành nghiên cứu đề tài này nhằm mục đích tìm hiểu giá trị dự đoán của CEA trong đánh giá đáp ứng với hóa trị ở bệnh nhân ung thư đại trực tràng giai đoạn tái phát, di căn mục tiêu sau: "Đánh giá sự thay đổi của CEA liên quan đến đáp ứng với hóa trị ở các bệnh nhân UTETT giai đoạn tái phát, di căn."

\section{II. ĐỐI TƯỢNG VÀ PHƯƠNG PHÁP NGHIÊN CỨU}

2.1. Đối tượng nghiên cứu. Đối tượng nghiên cứu là 81 bệnh nhân ung thư đại trực tràng giai đoạn tái phát, di căn không mổ được được điều trị từ năm 2017 đến năm 2021 tại khoa Nội 4, Bệnh viện $K$.

\section{Tiêu chuẩn lựa chơn:}

+ Các bệnh nhân được chẩn đoán UTĐTT giai đoạn tái phát hoặc di căn không có khả năng cắt bỏ được.

+ Được xác chẩn bằng kết quả mô bệnh hoc.

+ Có xét nghiệm CEA tăng trước điều trị: $>5 \mathrm{ng} / \mathrm{ml}$.

+ Được điều trị hóa chất bước 1 bằng phác đồ có Oxaliplatin hoặc Irinotecan làm nền.

+ Được theo dõi và đánh giá nồng độ CEA sau mỗi chu kì điều trị.

+ Được điêu trị tối thiểu là 6 chu kỳ hóa trị.

Tiêu chuẩn loại trừ: Bệnh nhân không thỏa mãn các tiêu chuẩn trên, mắc các bệnh lý gan thận tiến triển.

\subsection{Phương pháp nghiên cứu}

2.2.1. Thiết kế nghiên cứu:Nghiên cứu mô tả hồi cứu kết hợp với tiến cứu.

2.2.2. Cỡ mẫu nghiên cứu: Sử dụng phương pháp chọn mấu thuận tiện trên toàn bộ bệnh nhân đáp ứng tiêu chuẩn lựa chọn tại khoà Nội 4 , Bệnh viện $K$ tữ tháng 7/2017 đến tháng 7/2021. Có 81 bệnh nhân được chọn vào nghiên cứu.

2.2.3. Thu thập số liệu và tiêu chuẩn sử dụng: Thu thập số liệu qua mẫu bệnh án thiết kể sẳn

*Một số tiêu chuẩn dùng trong nghiên cứu:

\begin{tabular}{|c|c|c|}
\hline $\begin{array}{c}\text { Đáp ứng điều } \\
\text { trị }\end{array}$ & Theo CEA & Theo RECIST \\
\hline $\begin{array}{c}\text { Đáp ứng hoàn } \\
\text { toàn (complete } \\
\text { response, CR) }\end{array}$ & $0-5 \mathrm{ng} / \mathrm{ml}$ & Không thây u \\
\hline $\begin{array}{c}\text { Đáp ứng một } \\
\text { phần (partial } \\
\text { response, PR) }\end{array}$ & $\begin{array}{c}\text { Giảm } \\
>=30 \%\end{array}$ & $\begin{array}{c}\text { Giảm }>=30 \% \\
\text { đường kính lớn } \\
\text { nhất của khối u }\end{array}$ \\
\hline $\begin{array}{c}\text { Bênh tiến triê̂n } \\
\text { (progressive } \\
\text { disease, PD) }\end{array}$ & $\begin{array}{c}\text { Tăng } \\
>=20 \%\end{array}$ & $\begin{array}{c}\text { Tăng }>=20 \% \\
\text { đương kính lớn } \\
\text { nhất của khối u }\end{array}$ \\
\hline $\begin{array}{c}\text { Bênh ổn định } \\
\text { (stable diease, } \\
\text { SD) }\end{array}$ & $\begin{array}{c}\text { Không thỏa } \\
\text { mãn các tiêu } \\
\text { chuẩn trên }\end{array}$ & $\begin{array}{c}\text { Không thỏa mãn } \\
\text { các tiêu chuẩn } \\
\text { trên }\end{array}$ \\
\hline
\end{tabular}

2.2.4. Xử lý và phân tích số liệu. Các số liệu thu thập được mã hoá trên máy vi tính và xử lý bằng phần mềm thống kê SPSS 20.

2.2.5. Đạo đức nghiên cứu: Trung thực trong thu nhập số liệu. 


\section{KẾT QUẢ NGHIÊN CỨU VÀ BÀN LUÂ̂N}

3.1 Đăc điểm đối tượng nghiên cứu. Trong nghiên cứu của chúng tôi, tỷ lệ bệnh nhân nam:nữ là 43:38. Độ tuổi trung bình là 57 , dao động từ 30 đến 81 tuổi.69 bệnh nhân có kết quả mô bệnh học là ung thư biểu mô tuyến, chiếm $85,2 \%$ và chủ yếu có mức độ biệt hóa vừa. 64 bệnh nhân có tổn thương di cắn gan, di căn phổi xếp vị trí thứ hai với 20 người, đứng thứ ba là di căn phúc mạc và các vị trí khác; trong đó phần lớn là tổn thương đa ố, chiếm $87,7 \%$. Phác đồ hóa trị được sử dụng chứa Oxaliplatin chiếm $58 \%$ và $42 \%$ bệnh nhân được sử dụng phác đồ có chứa Irinitecan. Các đặc điểm bệnh nhân được trình bày cụ thể ở Bảng 1.

Bảng 1: Đặc điểm bệnh nhân nghiên cứu

\begin{tabular}{|c|c|}
\hline Đặc điểm & $\begin{array}{c}\text { Số lượng } \\
\text { bệnh nhẩn }\end{array}$ \\
\hline Nam : Nữ & $43: 38$ \\
\hline Độ tuối trung bình, năm \\
(khoảng) & $57(30-81)$ \\
\hline $\begin{array}{c}\text { Phân loại mô beênh hơc } \\
\text { Ung thư biểu mồ tuyến }\end{array}$ & 69 \\
Ung thư biểu mô chế nhầy & 6 \\
Không xác định & 6 \\
\hline Độ biệt hóa: 1 & 4 \\
2 & 58 \\
3 & 7 \\
\hline
\end{tabular}

\begin{tabular}{|c|c|}
\hline Không xác đinh & 11 \\
\hline $\begin{array}{c}\text { Số tốn thương di căn: Đơn ố } \\
\text { Đa ổ }\end{array}$ & $\begin{array}{l}10 \\
71\end{array}$ \\
\hline $\begin{array}{c}\text { Vị trí tái phát, di căn: Gan } \\
\text { Phổi } \\
\text { Hạch (thượng đòn, ổ bụng) } \\
\text { Phúc mạc } \\
\text { Khác } \\
\end{array}$ & $\begin{array}{c}64 \\
20 \\
11 \\
10 \\
4 \\
\end{array}$ \\
\hline $\begin{array}{l}\text { Nồng độ CEA trung bình trước } \\
\text { điêu trị,, } \mathrm{ng} / \mathrm{ml} \text { (khoảng) }\end{array}$ & $\begin{array}{c}986 \\
(4-36056) \\
\end{array}$ \\
\hline $\begin{array}{l}\text { Điều trị trước đó } \\
\text { Mới chẩn đoán } \\
\text { Đã có điều trị trước đó }\end{array}$ & $\begin{array}{l}62 \\
19\end{array}$ \\
\hline $\begin{array}{l}\text { Phác đồ hóa chất } \\
\text { Có chứa Oxaliplatin } \\
\text { Có chứa Irinotecan }\end{array}$ & $\begin{array}{l}47 \\
34\end{array}$ \\
\hline
\end{tabular}

3.2. Sự thay đổi nồng độ CEA huyết tương liền quan đến đáp ứng điêu trị. Nghiên cứu của chúng tôi cho thấy nồng độ CEA trung bình ban đầu trước điều trị là 986,0 (4$36056) \mathrm{ng} / \mathrm{ml}$; sau khi điều trị 3 chu kì giảm xuống còn $751,0(2-26772) \mathrm{ng} / \mathrm{ml}$, và sau 6 chu kì con số CEA trung bình là 465,9 (2-15241) $\mathrm{ng} / \mathrm{ml}$.

Tổng số 81 bệnh nhân có 85 lần đánh giá bằng cả CEA và CLVT, được phân loại thành đáp ứng hoàn toàn $(C R)$, một phần (PR), bệnh ổn định $(S D)$, và bênh tiến triển $(P D)$ theo tiêu chuẩn đã đề ra, chi tiết trong Bảng 2 ở dưới đây:

Bảng 2: Kêt quả đánh giá đáp ứng theo CEA và theo CLVT

\begin{tabular}{|c|c|c|c|c|c|c|}
\hline \multicolumn{2}{|c|}{ Đánh giá theo CLVT } & CR & PR & SD & PD & Tống \\
\hline \multirow{4}{*}{ Đánh giá } & CR & 1 & 11 & 2 & 0 & 14 \\
\cline { 2 - 7 } theo CEA & PR & 2 & 27 & 18 & 4 & 51 \\
\cline { 2 - 7 } & SD & 2 & 1 & 14 & 3 & 20 \\
\cline { 2 - 7 } & PD & 2 & 4 & 13 & 11 & 30 \\
\cline { 2 - 7 } & Tống & 7 & 43 & 47 & 18 & 115 \\
\hline
\end{tabular}

Tỷ lệ CR, PR, SD đánh giá theo CEA và theo CLVT lần lượt là 14/115 (12,2\%), 51/115 (44.3\%), $20 / 115(17,4 \%), 30 / 115(26,1 \%)$ và $7 / 115(6,1 \%), 43 / 115(37,4 \%), 47 / 115(40,9 \%), 18 / 115(15,7 \%)$.

Bảng 3: Giá trị của CEA trong dư báo đáp ứng khôi u khi sử dụng CLVT làm tiêu chuân

\begin{tabular}{|c|c|c|c|}
\hline & CR+PR & CR+PR+SD & PD \\
\hline Độ nhạy & $82,0 \%$ & $80,4 \%$ & $61,1 \%$ \\
\hline Độ đặc hiệu & $63,1 \%$ & $61,1 \%$ & $80,4 \%$ \\
\hline Giá trị dự đoán dương tính & $63,1 \%$ & $91,8 \%$ & $36,7 \%$ \\
\hline Giá trị dự đoán âm tính & $82,0 \%$ & $36,7 \%$ & $91,8 \%$ \\
\hline Độ chính xác chấn đoán & $71,3 \%$ & $77,4 \%$ & $77,4 \%$ \\
\hline
\end{tabular}

Giá trị của CEA trong đánh giá bệnh đáp ứng hoàn toàn và một phần có độ nhạy là $82 \%$, độ đặc hiệu $63,1 \%$, giá trị dự đoán dương tính và âm tính lần lượt là $63.1 \%$, với độ chính xác chẩn đoán $71.3 \%$.

Trong đánh giá bệnh tiến triển, đánh giá theo CEA có độ nhạy $61,15 \%$, độ đặc hiệu $80,4 \%$, độ chính xác chẩn đoán $77,4 \%$.

\section{BÀN LUẬN}

Trong điều trị UTĐTT, bên cạnh các công cụ như chụp CLVT, cộng hưởng từ hoặc siêu âm, việc tiến hành xét nghiệm CEA cũng được xem xét là một công cụ giúp theo dõi và đánh giá quá trình điều trị. Nồng độ CEA có xu hướng tăng rất cao ở những người bểnh tiến triển, tái phát và di căn nhiều vị trí và có xu hướng giảm xuống trở về bình thường nếu điều trị thành công. Tuy 
nhiên, điều này cũng phụ thuộc vào mỗi cá thể như sự đáp ứng thuốc hoặc tình trạng mắc bệnh kèm theo. Nếu CEA vẫn ở mức cao hoặc tăng lên thì tiên lượng xấu hơn và có nguy cơ tử vong[3]. Uu điểm của CEA so với các công cụ chẩn đoán hình ảnh khác là việc chi phí thấp và có kết quả nhanh chóng. CEA là một glycoprotein, trọng lượng phân tử 180.000 daltons do các tế bào ung thư tiết ra. Các tác giả đã thấy rằng CEA có mặt trong mô của nhiều loại ung thư nguyên phát cũng như thứ phát khác nhau thuộc đường tiêu hóa như dạ dày, thực quản, đại trực tràng, tụy, phổi, vú, ung thư sinh dục và ngay cả một số tổn thương lành tính. Chính vì vậy mà xét nghiệm CEA có độ nhay và độ đặc hiệu không cao. Tuy nhiên, nểu đánh giá sự tái phát di căn, CEA có thể có hiệu quả do xu hướng gia tăng bất thường nếu khổng được điều trị. ASCO cũng khuyến cáo xét nghiệm CEA mỗi 2 đến 3 tháng để theo dõi sau điêu trị và theo dõi đáp ứng với hóa trị̣[4]. Theo Colloca và cộng sự tổng quan 19 nghiên cứu trên thế giới, CEA có liên quan mật thiết với mức độ đáp ứng trên hình ảnh và khả năng sống còn của người bệnh[3].

Trong nghiên cứu này, sự thay đổi của CEA sau mỗi 3, 6 chu kỳ hóa trị được đánh giá dựa vào: sự thay đổi nồng độ trung bình của CEA, tỷ lệ tăng và giảm CEA. Từ đó đánh giá mối liên quan với đáp ứng của bệnh và tính ra độ nhạy, độ đặc hiệu, giá trị dương tính, giá trị âm tính và độ chính xác chẩn đoán của CEA trong đánh giá đáp ứng của bệnh.

Nồng độ trung bình CEA trước điều trị là 986,0 (4-36056) $\mathrm{ng} / \mathrm{ml}$, sau 3 chu kỳ là 751,0 (2-26773) $\mathrm{ng} / \mathrm{ml}$, sau 6 chu kỳ là 465,9 (2-15241) ng/ml.

Giá trị chẩn đoán của CEA. Trong nghiên cứu này, khả năng chẩn đoán của CEA cũng được đánh giá khi đối chiếu với tiêu chuẩn chẩn đoán RESICT. Kết quả cho thấy, Tổng cộng có 115 lượt đánh giá nồng độ CEA cho 81 người bệnh sau 3, 6 chu kỳ. Tỷ lệ người bệnh đáp ứng hoàn toàn theo CEA là $14 / 115(12,2 \%)$ và theo CLVT là $7 / 115(6,1 \%)$. Tỷ lệ áp ứng một phần là $51 / 115$ (44.3\%) theo CEA và $43 / 115(37,4 \%)$ theo CLVT. Tỷ lệ bệnh ổn định là 20/115 $(17,4 \%)$ theo CEA và $47 / 115(40,9 \%)$ theo CLVT. Tỷ lệ bệnh tiến triển là $30 / 115(26,1 \%)$ theo CEA và $18 / 115(15,7 \%)$ theo CLVT.

Giá trị của CEA trong đánh giá bệnh đáp ứng (bao gồm đáp ứng hoàn toàn và đáp ứng một phần): độ nhạy là $82,0 \%$, độ đặc hiệu $63,1 \%$, giá trị chẩn đoán dương tính $63,1 \%$; giá trị chẩn đoán âm tính $82,0 \%$, và chẩn đoán chính xác là $71,3 \%$.

Trong đánh giá bệnh không tiến triển (bao gồm bệnh có đáp ứng và bệnh ổn định) CEA có độ nhạy là $80,4 \%$, độ đặc hiệu $61,1 \%$, giá trị chẩn đoán dương tính 91,8\%; giá trị chẩn đoán âm tính $36,7 \%$ và chẩn đoán chính xác là $77,4 \%$.

Giá trị của CEA trong đánh giá bệnh tiến triển: độ nhạy là $61,1 \%$, độ đặc hiệu $80,4 \%$; giá trị chẩn đoán dương tính $36,7 \%$; giá trị chẩn đoán âm tính $91,8 \% \%$, và chẩn đoán chính xác là $77,4 \%$.

Kết quả này cao hơn so với một số nghiên cứu khác. Shinkins nghiên cứu trên 104 người bệnh trong 5 năm cho thấy độ nhạy của CEA là $50 \%$, độ đặc hiệu $93,3 \%$ trong chẩn đoán tái phát di căn [5].

Tác giả Gangmi Kim [2] và cộng sự nghiên cứu trên 48 bệnh nhân UTĐTT giai đoạn di căn cho thây độ nhạy, độ đặc hiệu và độ tin cậy của CEA trong dự báo bệnh tiến triển là $50 \%, 77 \%$ và $69 \%$, và ở nhóm bệnh nhân có tăng CEA ngay từ đâu thì độ nhạy, độ đặc hiệu cao hơn so với nhóm không tằng CEA.

Tác giả Wang khi nghiên cứu trên 40 bệnh nhân UTĐTT giai đoạn muộn được điều trị với tegafur-uracil cũng chỉ ra độ nhạy của CEA trong nhóm bệnh đáp ứng và khồng đáp ứng lần lượt là $62 \%$ và $70 \%$ [6]. Giá trị dự báo bệnh đáp ứng và bệnh tiến triến của CEA là $65 \%$ và $85 \%$.

\section{KẾT LUẬN}

Giá trị của CEA trong đánh giá bệnh đáp ứng (bao gồm đáp ứng hoàn toàn và đáp ứng một phần): độ nhạy là $82,0 \%$, độ đặc hiệu $63,1 \%$, giá trị chẩn đoán dương tính 63,1\%; giá trị chẩn đoán âm tính $82,0 \%$, và chẩn đoán chính xác là $71,3 \%$.

Trong đánh giá bệnh không tiến triển (bao gồm bệnh có đáp ứng và bệnh ổn định) CEA có độ nhạy là $80,4 \%$, độ đặc hiệu $61,1 \%$, giá trị chẩn đoán dương tính 91,8\%; giá trị chẩn đoán âm tính $36,7 \%$ và chẩn đoán chính xác là $77,4 \%$.

Giá trị của CEA trong đánh giá bệnh tiến triển: độ nhạy là $61,1 \%$, độ đặc hiệu $80,4 \%$; giá trị chẩn đoán dương tính 36,7\%; giá trị chẩn đoán âm tính $91,8 \%$, và chẩn đoán chính xác là $77,4 \%$.

Như vậy, qua nghiên cứu này, chúng tôi nhận thấy CEA có vai trò cung cấp thông tin hữu ích trong đánh giá đáp ứng bệnh, đặc biệt có độ nhạy cao trong chẩn đoán bệnh đáp và, độ đặc hiệu cao trong chẩn đoán bệnh tiến triển. Tuy nhiên, các nhà lâm sàng cũng cần kết hợp thêm nhiều phương pháp khác (lâm sàng, chẩn đoán hình ảnh...) để có thể đưa ra quyết định phù hợp nhất cho bệnh nhân của mình.

\section{TÀI LIÊU THAM KHẢO}

1. V. Heinemann, L. F. von Weikersthal, $T$. Decker và các cộng sự. (2014), "FOLFIRI plus 
cetuximab versus FOLFIRI plus bevacizumab as first-line treatment for patients with metastatic colorectal cancer (FIRE-3): a randomised, open-label, phase 3 trial", Lancet Oncol, 15(10), tr. 1065-75.

2. G. Kim, E. J. Jung, C. G. Ryu và các cộng sự. (2013), "Usefulness of carcinoembryonic antigen for monitoring tumor progression during palliative chemotherapy in metastatic colorectal cancer", Yonsei Med J, 54(1), tr. 116-22.

3. G. A. Colloca, A. Venturino và D. Guarneri (2019), "Carcinoembryonic antigen reduction after medical treatment in patients with metastatic colorectal cancer: a systematic review and metaanalysis", Int J Colorectal Dis, 34(4), tr. 657-666.

4. Mangu PB Meyerhardt JA, Flynn PJ et al
(2013), "Follow-up care, surveillance protocol, and secondary prevention measures for survivor of colonrectal cancer: American Society of Clinical Oncology clinical practice guideline endorsement", J Clin Oncol 31, tr. 4465-4470.

5. B. Shinkins, B. D. Nicholson, J. Primrose và các cộng sự. (2017), "The diagnostic accuracy of a single CEA blood test in detecting colorectal cancer recurrence: Results from the FACS trial", PLoS One, 12(3), tr. e0171810.

6. W. S. Wang, J. K. Lin, T. C. Lin và các cộng sự. (2001), "Carcinoembryonic antigen in monitoring of response to systemic chemotherapy in patients with metastatic colorectal cancer", Int J Colorectal Dis, 16(2), tr. 96-101.

\title{
NGÃ VÀ MộT SỐ YẾU Tố LIÊN QUAN TRÊN BỆNH NHẦN CAO TUỔI CÓ LOÃNG XƯO'NG
}

\author{
Nguyễn Thị Thanh Hải ${ }^{1}$, Nguyễn Xuân Thanh ${ }^{2,3}$, Nguyễn Ngọc Tâm²,3 \\ Vũ Thị Thanh Huyền ${ }^{2,3}$, Nguyễn Trung Anh ${ }^{2,3}$
}

\section{TÓM TẮT}

Mục tiêu: xác định tỷ lệ ngã và một số yếu tố liên quan ở người cao tuổi có loãng xương. Phương pháp: nghiên cứu mô tả cắt ngang trên 140 ngưới cao tuổi có loãng xương khám và điều trị bệnh viện Lão Khoa Trung Ương. Kết quả: độ tuổi trung bình của nhóm nghiển cứu là 73,2 $\pm 9,0$ tuổi, tỷ lệ ngã trên người cao tuổi có loãng xương là 34,3\%, trong đó $68,8 \%$ ngã vào buổi sáng, $62,5 \%$ ngã do trượt ngã, $16,7 \%$ ngã khi đứng dậy. Tỷ lệ gãy xương do ngã là 87,5\%. Không có mối liên quan giữa tuổi, giới, hoàn cảnh sống với ngã trên người cao tuổi có loãng xương $(p>0,05)$. Kết luận: Tỷ lệ gãy xương do ngã trên người cao tuổi có loãng xướng rất cao. Do vậy dư phòng ngã trên người cao tuổi có loãng xương là rất quan trong.

Tư'khóa: ngã, loãng xương, người cao tuổi, gãy xương.

\section{SUMMARY}

\section{FALLS AND SOME RELATED FACTORS} AMONG OLDER PEOPLE WITH OSTEOPOROSIS

Objectives: to determine the prevalence of falls and some related factors in the elderly with osteoporosis. Methods: A cross-sectional study included of 140 elderly with osteoporosis aged 60 and over who were treated at National Geriatric Hospital. Results: The average age of subjects was $73.2 \pm 9.0$ years old, the prevalence of falls in elderly people with osteoporosis was $34.3 \%$, of which $68.8 \%$ fell in the

${ }^{1}$ Bênh viên Đa khoa Tỉnh Thanh Hóa

${ }^{2}$ Bệnh viện Lão khoa Trung Ương

${ }^{3}$ Trường đai hoc Y Hà Nôi

Chịu trách nhiệm chính: Nguyễn Thị Thanh Hải

Email: nguyenhaibvdkt@gmail.com

Ngày nhân bài: 9.7.2021

Ngày phản biên khoa hoc: 3.9.2021

Ngày duyệt bài: 10.9.2021 morning, $62.5 \%$ falls due to slippage, $16.7 \%$ falls when standing up. The rate of fractures due to falls was $87.5 \%$. There was no relationship between age, gender, living situation with falls in elderly people with osteoporosis. Conclusion: The rate of fractures due to falls in elderly people with osteoporosis is very high. Therefore, it is necessary to prevent falls in the elderly with osteoporosis.

Keywords: fall, osteoporosis, elderly, fracture.

\section{I. ĐĂT VẤN ĐỀ}

Theo tổ chức y tế thế giới ngã là một sự kiện vô tình làm cho cơ thể ngã xuống mặt đất, sàn nhà, hoặc vị trí thấp hơn, ngoại trừ những trường hợp cố ý để thay đổi vị trí của chủ thể trên các đồ nội thất, trên tường hoặc những đối tượng khác [1]. Loãng xương và ngã đều là những vấn đề phổ biến ở người cao tuổi [2].

Loãng xương có liên quan đến những thay đổi trong sự cân bằng, hoạt động thể chất và tâm lý xã hội làm tăng nguy cơ ngã ở người cao tuổi [3]. Người cao tuổi bi loãng xương có tỷ lê và tân suất bị ngã cao hơn so với người không bị loãng xương [2]. Ngã ở người cao tuổi là một vấn đề nghiêm trọng để lai hâuu quả nănng nề cho các cá nhân, gia đình và hệ thống y tế. Tuy nhiên, chúng ta có thể dự phòng được những nguy cơ ngã ở người cao tuổi nói chung và người cao tuổi có loãng xương nói riêng bằng nhiêu biện pháp khác nhau.

Chúng tôi thực hiện nghiên cứu này nhằm xác định tỷ lệ ngã và một số yếu tố liên quan trên đối tượng người cao tuổi có loãng xương, qua đó giúp các nhân viên y tế cũng như những nhà chính sách y tế có thêm những bằng chứng để 